\title{
Efficiency of gaming technology in the process of foreign language acquisition
}

\author{
O.V. Smolovik ${ }^{11 *}$, M.A. Kushnyr ${ }^{2}$, and L.Yu. Shobonova ${ }^{3}$ \\ ${ }^{1}$ Minin Nizhny Novgorod State Pedagogical University, Nizhny Novgorod, Russia \\ ${ }^{2}$ Minin Nizhny Novgorod State Pedagogical University, Nizhny Novgorod, Russia \\ ${ }^{3}$ Minin Nizhny Novgorod State Pedagogical University, Nizhny Novgorod, Russia
}

\begin{abstract}
The article deals with the study of the gaming technology in teaching a foreign language to primary school children and its influence on their motivation. Nowadays it is relevant to start mastering a foreign language at primary school. The article presents the psychological and pedagogical characteristics of primary school children, emphasizes the importance of academic motivation, reveals the peculiarities of the gaming technology, gives examples of its practical application and shows the results of the experimental research identifying the impact of this method on the level of young learners' motivation. The purpose of the article is to study the influence of practical application of the gaming technology on primary school children's motivation in the process of the foreign language acquisition. The methodology of the study is a theoretical analysis of psychological research, empirical research methods, qualitative and quantitative analysis of empirical data. The results show that the use of the gaming technology increases academic motivation of primary school children.
\end{abstract}

\section{A problem statement}

Nowadays there is a tendency for successful professional implementation of graduates who speak a foreign language at a level that enables them to work in cooperation with foreign partners, taking into account the foreign experience of their colleagues, using foreign sources of information, etc. In order to be able to speak the foreign language fluently, it is recommended to start studying it since childhood. It is well known that early learning of the foreign language is an actual and perspective area of modern methods of teaching foreign languages, as learning activity is the principal activity for primary school children and primary school age is a susceptible period for the formation deep and lasting knowledge that is preserved in a long-term memory.

Education in primary school is one of the most important and difficult periods in children's lives. It is accompanied by imminent stress: changes in routine increases psychoemotional strain. The tasks that the school sets for children are not directly related to their previous activities but require physical and intellectual efforts. The whole set of factors

1*Corresponding author: ipcs-profped@yandex.ru 
now affects a child: the teacher and his or her personal qualities, the new team (classmates), the new daily routine, long-term restriction of physical activity and a large number of new responsibilities.

There are several features which characterize young learners: naivety, impressionability and receptivity, open-mindedness, trustfulness, playful attitude towards different situations, sincere recognition and submission to authority. However, some researchers point to rivalry between primary school children, unfriendliness and lack of empathy, inability to empathize with and rejoice at classmates' achievements [1]. In L.I. Bozhovich's opinion, the transition from preschool to school is characterized by a decisive change in the child's system of relationships and the way of life [2]. At the same time, a successful transition to a new stage of life and the formation of all the necessary new structures (cognitive character of memory, purposeful and arbitrary perception, visual-figurative thinking, turning into verbal-logical thinking by the end of education in primary school, etc.) [3] require motivation.

\subsection{The objective of the work}

The problem of motivational determination of activity is widely reflected in both Russian and foreign scientific works. Most of the Western theories: psychoanalysis, behavioural theory, K. Lewin's field theory, concept of cognitive dissonance of L. Festinger, D. McClelland's theory of motivational needs, H. Heckhausen's theory of motivation, study the motivational mechanisms of personality. The fundamental theoretical and methodological foundations for studying the essence and nature of motive and motivation were laid by K.A. Abulkhanova-Slavskaya, V.G. Aseev, L.I. Bozhovich, V.K. Vilyunas, A.N. Leontiev, W.G. Leontiev, M.S. Magomed-Eminov, A.B. Petrovsky, S.L. Rubinstein, D.N. Uznadze, V.D. Shadrikov, P.M. Jacobson [4]. According to numerous researchers, the motivational sphere is the core of personality [5]. Today, there are over 100 different definitions of motivation, reflecting the complexity of the subject [6]. From the point of view of A.N. Leontiev, motivation is a set of driving forces that motivate a person to engage in activities with a certain target orientation [7]. On the basis of general theoretical survey about the essence, structure and mechanisms of motive and motivation, a number of studies have been carried out so far, which makes it possible to study the specifics of certain types of motivation - academic, professional and sport motivation [4].

The problem of academic motivation, both in Russian and foreign psychology, is essential for modern school [8]. Without motivation, the activity is not carried out, or is not productive. Academic motivation means a combination of integrity and structure of learning motives [9]. The amount of effort applied to learning activities depends on young learner' self-perception in a particular situation. That is why the whole learning process should be interesting. The learning process is multi-motivated, i.e. a number of motives determines child's activity.

There are three main blocks in the formation of learning motives: emotional, motivational and cognitive. Each subsequent block appears on the basis of the previous one and becomes a priority. Depending on the learning situation, one block may penetrate or complement another. Thus, young learners' emotional and volitional manifestations are the motives for achieving a goal. In order to develop the ability to formulate and achieve goals, primary school children needs to learn how to manage their behaviour and emotions. This ability leads to the development of independence, and it helps to set goals and foresee the result of activities. Initiative and curiosity appear simultaneously, and regulate young learners' activities. The main task of the emotional block is to arouse children's curiosity, the cause of interest. The purpose of the motivational block is to teach goal-setting within 
the learning process. The formation of learning activity is the aim of the cognitive block [10].

Focusing on the motivation of learning the foreign language, we should notice that scientists distinguish two types: instrumental and integrative motivation [11]. These types can be conditionally correlated with external and internal motivation. Since instrumental motivation is a reflection of external needs, the purpose of learning the foreign language is not learners' personal desire, but a need from outside. Therefore, teachers should not rely only on instrumental motivation and consider that instrumental motivation is sufficient for effective learning the foreign language; it is important to develop integrative motivation.

Integrative motivation is a reflection of internal needs and comes from a desire to identify with the culture of the country where the foreign language is spoken. In this case, the aim of learning the foreign language is learners' internal needs. For example, if learners attach more importance to meeting and communicating with different people and language becomes a tool to understand foreigners and their way of life, so we may talk about integrative motivation. Researchers believe that integrative motivation correlates with better success in the foreign language acquisition $[12,11]$. Nevertheless, it is necessary to keep balance between integrative and instrumental motivation when teaching the foreign language. Only with a reasonable combination of these two types, it is possible to master the foreign language successfully.

It should be noted that primary school children are very eager to learn, and they get the "good" and "excellent" marks. The leading motives are praise and encouragement from adults, motive for new knowledge and motive for working during the lessons, especially if lessons are held in an entertaining manner. While actively learning, young learners get good marks, which are a source of pride and other encouragements, as well as a guarantee of their emotional stability.

Therefore, it is particularly important to pay attention to the process of forming and increasing motivation through various methods and techniques including gaming technologies, as "the quality of students' training depends on educational technologies" [13].

\section{Materials and the results of the research}

The aim of our research is to investigate the effectiveness of the gaming technology in teaching the foreign language to primary school children.

The objectives of the study are: 1) to study the essence of the method and the possibilities of its application in teaching young learners the foreign language; 2) to apply a number of gaming technologies in the process of teaching the primary school children; 3 ) to identify the impact of the gaming technology on the young learners' motivation. The methodological basis of the research was formed by a review of psychological and pedagogical works on the research problem, empirical research methods, quantitative and qualitative analysis of empirical data.

Game-based forms of training are actively developed and used in the educational process of Russian and foreign educational institutions in the training of a wide range of specialists [14]. Game is a type of activity in situations aimed at recreating and assimilating social experience, in which self-management of behaviour develops and improves [15].

"Gaming technology" in pedagogy is a fairly extensive group of methods and techniques for organizing the teaching process in the form of various pedagogical games [15].

L.S. Vygotsky, A.N. Leontyev, D.B. Elkonin and many other scientists were engaged in the development of the gaming methodology, determination of the social nature of games and the significance for learner's development [16].Gaming technologies contain several 
components: motivational, content-activity, intellectual, communicative, effective and evaluative-prognostic. Gaming technologies are characterized by the following principles: consistency, reproducibility, effectiveness, activity, dynamism, collectivity, feedback, problem-solving, independence. Gaming technologies contribute to the activation of thinking; increase motivation and involvement of students in the learning process [17].

Game as a learning phenomenon is a unique concept and it is studied through two main approaches: corrective and diagnostic [18], both of them are aimed at displaying the personal qualities, while being limited by the framework of the generated situation. The corrective approach in teaching the English language is divided into two subtypes: revealing the personal qualities when a person corrects his or her own activities, and the teacher's correction of learner's activities. It is important to note that the gaming methodology fully consists of the principle of integration, where one of the main goals is to teach everybody how to interact.

It is also worth considering that there is always a competitive moment in the game, that is why it is much easier for a teacher to monitor the improvement of learners' knowledge. This way expresses the diagnostic function of the game. The corrective function helps learners to cope with the assimilation of material, supported by positive emotional experience, and to master both the social roles of the participants and the ways of applying new information.

In addition, the game as a teaching method can be considered as the system of projectbased learning, which according to E.S. Polat: "allows learners to solve a problem by means of their independent actions, with the mandatory presentation of the results" [19].

Gaming technology is a compound, covering a certain part of the learning process and united by a common content, plot and character. It includes games and exercises that form the ability to distinguish the main characteristic features of objects, compare and contrast them; groups of games to generalize objects according to certain features; groups of games in the course of which young learners develop the ability to distinguish real phenomena from unreal ones; groups of games that develop the ability to control oneself, quick reaction to a word, phonemic hearing, ingenuity, etc. At the same time, the game story develops in parallel with the main content of learning, helping to activate the learning process and master the learning elements [15]. As part of the game, the teacher can set up exercises for the development of associative memory, which allows to actively use new vocabulary not only at school but also in real life. Of course, it is also worth considering that the whole learning process cannot take place in a game form.

This method has a number of advantages: it can actualize thinking through the English language, increase the motivation to learn the foreign language, knowledge of which brings significant benefits to learners' lives. Moreover, one of the advantages of the gaming technology is the possibility of using it at any stage of learning process if learners have the necessary base of knowledge they will develop. Using the game at the initial stage allows the group to get involved in the language learning process and interest primary school children in language games that helps to find an individual approach to each of them. Using the game at the border checkpoint help to form the degree of learning, adjust the further learning process and lead young learners to interpersonal communication within the framework of the English language, develop reading skills and independent speech activity, i.e. within the compensatory function it makes up for the lack of practical applications of knowledge. In addition, the pedagogical value of the game lies in the fact that it becomes the strongest motivational factor, and primary school children's personal attitudes and motives guide their learning activity [20].

The methodology of teaching foreign languages to young learners includes a substantial amount of games that are actively used with primary school children. We would like to offer the following small selection of the games as examples: 
1) "Crocodile". This game is widely used, for example, to reinforce the vocabulary on the topic "Animals", and to develop young learners' creativity. The rules are simple: the presenter portrays any animal, while the other learners guess and name it. He cannot make sounds, such as "meow", etc. The learner who guesses the word first becomes the presenter. This technology is also used to remember the vocabulary on the topic "Daily activities". The presenter leaves the classroom and the group of primary school children stands near the blackboard. Each young learner depicts one of the actions by means of gestures and facial expressions. The teacher then tells the presenter: "What is every pupil doing?". The presenter may response the following: "This boy is doing his homework", "That girl is combing her hair", "That boy is eating" and so on.

Due to this game, teachers may quickly develop young learners' skill of using a syntactic structure such as "It is", in combination with the vocabulary on the topic "Weather". For example, "It is sunny today", "It is snowy today", etc. In this case, primary school children depict weather phenomena in movements. The use of this gaming technology intensifies young learners' activity and promotes the unintentional (i.e. what happens during the game, without making any efforts) assimilation of the material and its subsequent use in speech without significant difficulties.

2) "Swap places - Switch places". Eight young learners play this game. The primary school children sit in a circle, and the teacher gives them cards with images of animals, fruits, etc. All the cards are duplicated, and there must be at least two identical cards in a set. The presenter says a word, and children who have heard their word must switch places and say their word. This technology can be used both at the stage of consolidating new lexical units and at the control stage.

3) The game "Where did the camel run away?" There are a lot of toys on the table animals whose names are well known to young learners. The command is "Close your eyes!" At this time, one of the toys is removed (e.g. a camel) and hidden in the classroom. The teacher says that something ran away from the zoo because it was not well fed. "What ran away?" Firstly young learners guess who ran away: "Is it a bear?", "Is it a fox?". If primary school children have not guessed correctly, they continue to recognize it by signs: "Is it big (brown...)?" Then they guess where the animal has run away: "Is it under the bookcase (chair...)?" While asking questions, primary school children practice the grammatical structure of the questions, topical vocabulary "Animals", "Furniture", adjectives, prepositions in combination with physical activity (when children ask questions, they not only acquire the skill of using grammatical structure and vocabulary units, but also depict the lexical meaning of words with movements, which helps to relieve the physical strain caused by sitting at the desk). Moreover, teachers may use this technology with many other topics [21].

4) "Walk through the classroom". This activity is efficient for children and adults. The teacher needs several objects or props to use. The teacher shows the actions and name them. Then the teacher names the actions and asks the primary school children to show them. Examples: - "You open the door." - "You come to the blackboard." - "You take a chalk." "You close the window." -"You take your pencil."-"You look at him." [21].

5) "Role-playing games - pantomimes". This game is also popular among adult students, but it is especially useful for primary school children. Give each young learners a role, but he/ she has to play it without words. For example, the first learner needs to go to the clinic and he asks how to get through. But he has lost his voice and cannot say a word. The second young learner stops him on the street and asks to show the way, but this person (the first) cannot speak, the second young learner has to understand his gestures in order to find out where he needs to go [21].

6) "Hands up!" - An active game for attentiveness. The presenter's task is to confuse the children by naming one command, while doing the other. For example, the presenter says 
"Clap hands!", while stomping. Primary school children should be very attentive when following the instructions given by the presenter. If a young learner makes a mistake, he is out of the game. The most attentive pupil becomes the presenter [21].

7) "Transformations". Young learners make a circle and by touching each other with a "magic wand", they "transform" each other and "transform" themselves. Examples of primary school children's responses: "I am a princess and you are a mouse." "I am not a mouse, I am a kitten and you are a monster." "I am not a monster. I am a pilot and you are a sandwich." In this case, young learners practice the use of the verb "To be" in affirmative and negative sentences as well as new lexical units, or update the previously studied vocabulary [21].

In order to determine the effectiveness of the use of the gaming technology in teaching young learners the foreign language and its influence on primary school children's motivation we carried out the experimental research. The sample consisted of third-grade pupils of the "Lyceum No. 40" (Nizhny Novgorod) and the "Author's Academic School No. 186" (Nizhny Novgorod). The experimental study was conducted in two stages: before using the gaming technologies in foreign language lessons and after their active application (at the beginning of the academic year and at the end of the second academic term, respectively).

To identify the level of young learners' academic motivation, we used T.D. Dubovitskaya's test questionnaire "Methodology for diagnosing the orientation of academic motivation". The purpose of this methodology is to identify the focus and level of internal motivation of pupils' learning activity in studying specific academic disciplines, in particular the foreign language. This method allows teachers to identify the existing level of learners' academic motivation and monitor its changes when using various forms, methods and techniques. Here are the results:

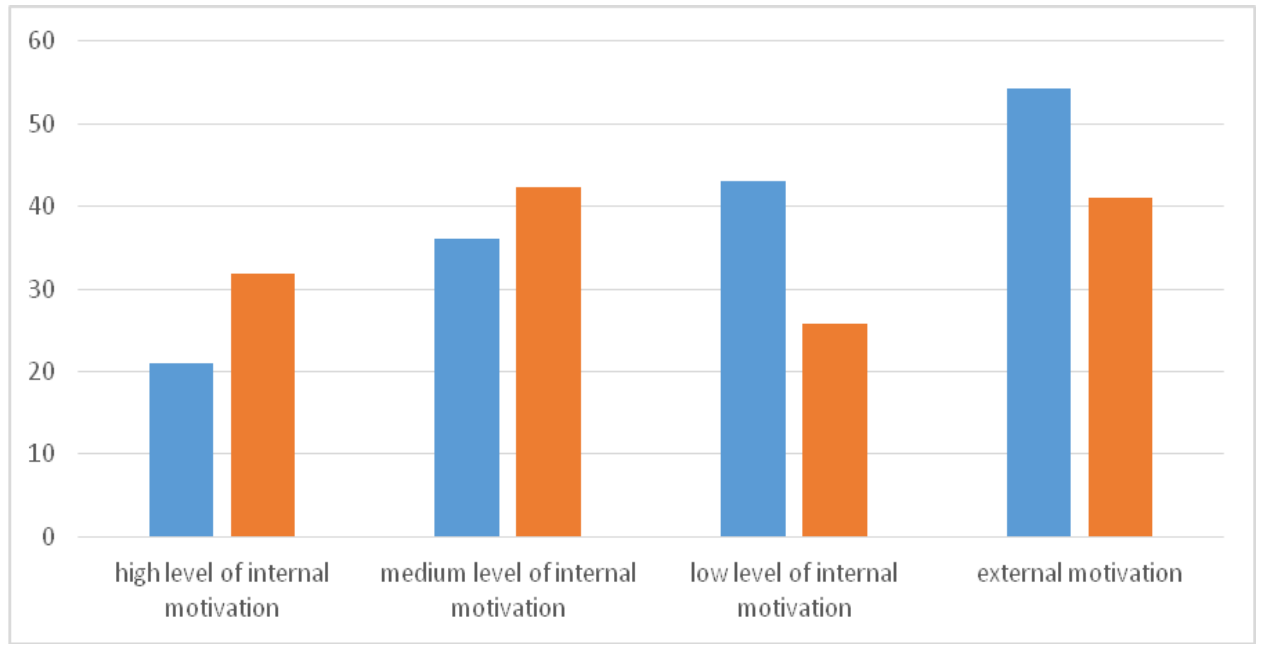

Fig. 1. Young learners' academic motivation before and after using gaming technology.

Before the use of the gaming technology, $45.8 \%$ of the test subjects had an internal motivation, which indicated their interest, desire to acquire knowledge in this discipline and active learning position. Among them, $20.9 \%$ of the young learners showed a high level of internal motivation, $36 \%$ of the respondents had a medium level of internal motivation, and $43.1 \%$ of those primary school children had a low level of internal motivation. We identified external motivation to learn a foreign language among the $54.2 \%$ of the subjects, which indicated that the primary school children's learning activity was motivated by external incentives, which might include academic progress, evaluation of their results by 
third person, and in some cases, material incentives (e.g. gifts from parents). The revealed indicators were explained by the fact that the young learners were very susceptible to assessing their activities, they considered teachers and parents as authorities, and tried to earn praise and approval.

When diagnosing the levels of academic motivation after a number of lessons including the game technology, the level of young learners' internal motivation increased to $58.9 \%$. That fact indicated that more primary school children became genuinely interested in the subject and the process of learning the foreign language, their learning activity was stimulated by internal motives, they felt the desire to acquire new knowledge, and the learning process was exciting for them, their skills developed in the form of a game, which was optimal in accordance with their psychological, pedagogical and age characteristics. Among the young learners with internal motivation, 31.9\% showed a high level, which is $11 \%$ higher than before the use of the gaming technology; $42.4 \%$ had a medium level of internal motivation, and $25.7 \%$ of the primary school children demonstrated a low level of internal motivation (versus $43.1 \%$ ), that is a significant indicator of the effectiveness of using the gaming technology in the foreign language lessons. External motivation was found in $41.1 \%$ of the test subjects.

The results indicate that gaming technologies included in the teaching process can serve as active means of increasing young learners' motivation, which in turn leads to greater involvement in the learning process, automation of skills, improvement of the quality of knowledge and optimization of the process of learning the foreign language.

\section{Conclusions}

A brief overview of the main psychological, pedagogical and age characteristics of primary school children is reflected in this study. To a greater extent, academic motivation affects the success of the learning activity of young learners; and young learners' academic progress and their prospects for further intellectual and personal development depend on its type (internal, external) and level (high, medium, low). The gaming technology is considered as the optimal method of teaching the foreign language to primary school children. The experimental research proved the effectiveness of this method. According to the study, teachers of foreign languages can use gaming technologies when teaching primary school children, and the results of the experimental research can be applied in further psychological work.

\section{References}

1. T.A. Runova, E.G. Gutsu, M.D. Nyagolova, The study of the formation of relations of educational cooperation of younger schoolchildren, Vestnik of Minin University. 7 (3), 12 (2019)

2. N.V. Pilipko, Hello, school! Adaptation lessons with first-graders: Practical psychology to the teacher (Ed. Pilipko N.V., M.,: "Perspective", 2002)

3. G.K. Dzhumazhanova, N.I. Koishibaeva, D.A. Zhunisbekova, Z.A. Iztaev, Psychological basics of primary school education, International Journal of Applied and Fundamental Research. 12 (1), 183-187, access mode: https://appliedresearch.ru/ru/article/view?id=7843 (2015)

4. A.S. Galchenko, Features of motivational structure of civil activity of teenagers with different status of civil identity, Vestnik of Minin University. 7 (3), 8 (2019) 
5. V.G. Aseev, Motivation of Behaviour and Personal Development, p. 159 (Moscow, 1976)

6. M.V. Arkhipova, E.E. Belova, Y.A. Gavrikova, T.E. Nikolskaya, T.N. Pleskanyuk, Overview of the Educational Motivation Theory: A Historical Perspective, Lecture Notes in Networks and Systems, 87, 324-331 (2020)

7. A.N. Leontiev, Activities. Consciousness. Personality, 2nd ed., p. 304 (Moscow: Politizdat, 1977)

8. O.V. Smolovik, The impact of the total physical response method on pupils' motivation, Educational resources and technologies. 4 (29), 28-33 (2019)

9. B. Werner, A theory of motivation for some classroom experiences, Journal of Educational Psychology, 240 (1999)

10. T.O. Gordeeva, O.A. Sychev, A.N. Sidneva, D.V. Pshenichniuk, Academic Motivation of Elementary School Children in Two Educational Approaches - Innovative and Traditional, Psychology in Russia: State of the Art, 11 (4), 22-39 (2018)

11. R. Gardner, Social Psychology and Second Language Learning: The Role of Attitudes and Motivation (London: Edward Arnold, 1985)

12. Ed.L. Deci, R.M. Ryan, Intrinsic Motivation and Self-Determination in Human Behavior (New York: Plenum, 1985)

13. M.L. Gruzdeva, O.I. Vaganova, S.N. Kaznacheeva, N.V. Bystrova, A.V. Chanchina, Modern Educational Technologies in Professional Education, Lecture Notes in Networks and Systems, 73, 1097-1103 (2020)

14. V.V. Bulgakov, Business game as method of training of cadets of emercom, Vestnik of Minin University, 8 (3), 1 (2020)

15. T.M. Mikhailenko, Gaming technologies as a kind of pedagogical technologies, Pedagogy: traditions and innovations: materials of I International Scientific Conf., p. 140-146, access mode: https://moluch.ru/conf/ped/archive/19/1084/ (Chelyabinsk, October 2011)

16. O.V. Budakova, Gaming technology as an effective means of activating the learning process in a foreign language lesson, Pedagogical skills: materials of the International scientific conference (Moscow, April 2012)

17. O.I. Vaganova, Gaming technologies in professional education, International Journal of Innovative Technology and Exploring Engineering 8(12), 2059-2063 (2019)

18. V.V. Bondarenko, M.V. Lanskikh, Y.V. Bondarenko, Modern pedagogical technologies (Kharkov: KhNADU, 2011)

19. E.S. Polat, Project method, article on the Russian Academy of Education website. Modern Gymnasium: Views of Theorist and Practice (Edited by E.S. Polat, 2000)

20. V.I. Ishchenko, Gaming technologies in the educational process, International Journal of Experimental Education, 11 (6), 866-868, access mode: http://expeducation.ru/ru/article/view?id=9498 (2015)

21. O.V. Smolovik, L.Yu. Shobonova, Physical response method in teaching a foreign language, Problems of modern pedagogical education, 67(1), 337-339 (2020) 